\title{
Study of modifiable risk factors associated with learning abilities in MBBS students
}

\author{
BN Mishra ${ }^{1}$, Priyanka Barjatya ${ }^{2 *}$, Naveen Kumar Singh Panwar $^{3}$, DS Chouhan ${ }^{4}$, S C Mohapatra ${ }^{5}$ \\ ${ }^{1}$ Professor, ${ }^{2,3}$ Post Graduate $I I^{\text {nd }}$ Year, ${ }^{4}$ Statistician, ${ }^{5}$ Dean Academic and Professor, Dept. of Community Medicine, ${ }^{1-4} \mathrm{R} D$ \\ Gardi Medical College, Ujjain, Madhya Pradesh, ${ }^{5}$ SGT University Gurugram, Haryana, India
}

*Corresponding Author: Priyanka Barjatya

Email: barjatya12345@gmail.com

\begin{abstract}
Introduction: Healthy body is the basis for healthy mind and sound learning. Factors affecting physical health can influence one's learning abilities. BMI, neck girth, breakfast eating habits, resting blood pressures are surrogates of physical health; when they err different learning skills may go hayward.

Materials and Methods: A cross-sectional study was carried out on first year medical students in a medical college in western part of central India. 127 complete entries were evaluated by 'Metacognitive Awareness Inventory'. Obesity was assessed by BMI and Neck Circumference, and resting blood pressure measured by standing mercury sphygmomanometer. Breakfast eating behaviour was assessed by semi structured close-ended questionnaire. The data were coded and analysed by SPSS version 20. The level of significance was assigned at $\mathrm{p}<0.05$.

Results: On Pearson correlation analysis it was observed that metacognitive awareness inventory $(r=-0.191, p<0.05)$, regulation of cognition power $(r=-0.197, p<0.05)$, and information management strategy $(r=-0.347, p<0.01)$ were negatively co related with BMI. The breakfast eating behaviour also showed negative relationship with knowledge about cognition ( $\mathrm{r}=\mathrm{-}$ $0.191, \mathrm{p}<0.05)$ and comprehension monitoring $(\mathrm{r}=0.180, \mathrm{p}<0.05)$, whereas the blood pressure showed negative relationship with information management strategy $(r=-0.244, \mathrm{p}<0.01)$.

Conclusion: Obesity favouring factors and increased BP correlated strongly with diminished metacognition power, whereas daily breakfast eating had strong relationship with improved knowledge about cognition and comprehension skills.
\end{abstract}

Keywords: Learning skills, Metacognition awareness inventory, Breakfast habits, Obesity, Blood pressure.

\section{Introduction}

Metacognition is the ability to examine how you process thoughts and feelings. This ability encourages students to understand how they learn best. It also helps them to develop self-awareness skills that become important as they get old. ${ }^{1}$

Any health condition whether 'physical or cognitive' has many manipulators. Metacognitive health of an individual is no exception. It is influenced by modifiable factors like breakfast eating habits, BMI, resting blood pressure and other obesogenic indicators.

A gap of about 10 to 12 hours between dinner and breakfast leads to low blood glucose levels and habitually missing breakfast act as an antagonistic factor that adversely affect cognitive performance. ${ }^{2}$ Breakfast eaters tend to have higher basal metabolism, and have less craving for food which reduces the chances of obesity. A number of studies had reported that skipping breakfast lowers cognitive function and work efficiency. ${ }^{3}$

Overweight and obesity, as indicated by increased body mass index (BMI), has been found to be associated with a higher risk of cognitive decline. It is an important risk factor for vascular disease which can also influence executive function via the vascular pathway. ${ }^{4}$

The harmful effects of blood pressure have been long recognised (1960s). A study on psychomotor speed of air traffic controllers and pilots demonstrated reduced performance in individuals with hypertension ${ }^{8}$. Blood pressure is likely to underlie the association between obesity and cognition. ${ }^{6}$ Both high and low blood pressure have been linked with cognitive decline and dementia. The person with high blood pressure has reduced abstract reasoning 
(executive dysfunction), slowing of mental processing speed, and memory deficits. ${ }^{7}$ Most of the vascular alterations induced by hypertension contribute to cognitive impairment by leading to hypoperfusion, ischemic and haemorrhagic stroke, and white matter injury. ${ }^{10}$

Considering above factors the present study was designed to assess the relation of metacognition with breakfast eating habits, obesogenic health indicators and resting blood pressure in $1^{\text {st }}$ year MBBS students.

\section{Hypothesis}

It was hypothesized that learning through metacognitive process would most likely correlates to breakfast eating habit, obesity predisposing anthropometries and resting blood pressure in new entrants to medical college.

\section{Aim and Objectives}

To assess existence of any correlation between learning skills by 'metacognitive awareness inventory' and its subcomponents against variables like breakfast eating behaviour, obesity indicators, and resting blood pressure among first MBBS entrants.

\section{Materials and Methods}

A cross sectional study was conducted among I MBBS students from June to August 2019 after obtaining permission from the competent authorities. Participants were explained about all the procedural details of the study before asking for informed consent.

The study was conducted in two phases. In the first phase of the study metacognitive awareness inventory (MAI) questionnaire was handed over to the consenting participants and adequate time (25 minute) was assigned for completing it. Through MAI questionnaire different learning skills of the participants were evaluated. MAI does this by two major components namely; 'Knowledge about cognition', and 'Regulation of metacognition'. The 'knowledge about cognition' consists of statements on declarative knowledge, procedural knowledge, and conditional knowledge whereas the 'regulation of metacognition' covers a wide perspective involving planning or goal setting, organizing and managing information, and monitoring that sharpens one's intellect.

In the second phase of study anthropometric information were collected. Body weight was measured by a portable weighing scale with a maximum recording capacity of $125 \mathrm{~kg}$ with a margin of error $\pm 100 \mathrm{gm}$. Individuals were asked to remove shoes and heavy clothes prior to weighing. Height was measured by stadiometer (SECA 213) on individuals without shoes on. BMI was calculated by the formula weight in $\mathrm{kg} / \mathrm{height}$ in meter square. BMI guideline for Asian Indian populations was adopted. The BMI value of $<18.5 \mathrm{~kg} / \mathrm{m}^{2}$ was considered underweight, $18.5-$ $22.9 \mathrm{~kg} / \mathrm{m}^{2}$ normal, 23.0-24.9 overweight, and >25 $\mathrm{kg} / \mathrm{m}^{2}$ as obese. Neck circumference (NC) was measured by a standard calibrated measuring tape just below the level of 'Adam's Apple'. The normal cut off value of $\mathrm{NC}$ for male was $<37 \mathrm{~cm}$, and females $<34$ $\mathrm{cm}$. BP was measured on the left arm in a sitting position with the subject in a relaxed state by mercury sphygmomanometer (Diamond deluxe, BP apparatus, Pune, India) with the available pre-supplied small adult arm cuff size $22 \times 11 \mathrm{~cm}$. Two BP readings were taken five minutes apart and the average calculated to estimate the final blood pressure. JNC -8 guidelines was used for interpretation of $\mathrm{BP}$ recording.

\section{Statistical analysis}

Data entry and statistical analysis were done using SPSS v 20. The results were explained as descriptive and inferential analysis.

\section{Results}

There were 127 study participants consisting of 69 males and 58 females with a mean age of 19.78( \pm 1.076) years. The means and standard deviations for BMI was $21.46 \mathrm{~kg} / \mathrm{m}^{2}( \pm 3.82)$, neck girth was 32.95 $\mathrm{cm}( \pm 4.07)$, systolic BP was $123.25( \pm 12.94) \mathrm{mm} \mathrm{Hg}$, diastolic BP at 78.03( \pm 7.84$) \mathrm{mm} \mathrm{Hg}$, Metacognitive awareness inventory score at 40.31( \pm 5.824$)$, knowledge about cognition at 12.91( \pm 2.29$)$, and regulation of cognition was $27.41( \pm 4.43)$. Mean scores of subsections of Knowledge about cognition like: Procedural knowledge, Declarative knowledge, Conditional knowledge was 3.17( \pm 0.83$), 5.71( \pm 1.48)$ and $4.03( \pm 0.98)$ respectively. Similarly mean scores 
and standard deviations of subsections of Regulation of Cognition like Information Management Strategies, debugging strategies, Planning, Comprehension monitoring, and Evaluation were 8.35( \pm 1.45$)$, $4.39( \pm 7.92), \quad 5.14( \pm 3.96), \quad$ and $\quad 4.33( \pm 1.39)$ respectively. The overall reliability of metacognitive awareness inventory was 0.752 (Cronbach's alpha).

$14.9 \%$ of participants were obese and $17.3 \%$ over weight as per adopted BMI criteria. Employing neck girth for detection of obesity $15.7 \%$ was found to be obese. A high percentage i.e. 83(65.54\%) of participants were pre hypertensive and $18(16.5 \%)$ had stage I HTN. Most subjects 83(65.3\%) were daily breakfast eaters. The descriptive details of explorative variables with respect to age and gender are presented in Table 1.

Table 1: Descriptive analysis of explorative variables with regards to age and gender

\begin{tabular}{|c|c|c|c|c|c|c|c|c|c|c|c|}
\hline & \multicolumn{4}{|c|}{ Age $<20$ years } & \multicolumn{4}{|c|}{ Age $>20$ years } & \multirow{3}{*}{$\begin{array}{l}\text { Total } \\
\text { count }\end{array}$} & \multirow{3}{*}{$\begin{array}{l}\text { Total } \\
\text { count } \\
\text { N\% }\end{array}$} \\
\hline & & \multicolumn{2}{|c|}{ Female } & \multicolumn{2}{|c|}{ Male } & \multicolumn{2}{|c|}{ Female } & \multicolumn{2}{|c|}{ Male } & & \\
\hline & & Count & $\begin{array}{l}\text { Table } \\
\mathrm{N} \%\end{array}$ & Count & $\begin{array}{l}\text { Table } \\
\mathrm{N} \%\end{array}$ & Count & $\begin{array}{l}\text { Table } \\
\mathrm{N} \%\end{array}$ & Count & $\begin{array}{l}\text { Table } \\
\mathrm{N} \%\end{array}$ & & \\
\hline \multirow[t]{4}{*}{ BMI } & Underweight & 5 & $3.9 \%$ & 9 & $7.1 \%$ & 8 & $6.3 \%$ & 5 & $3.9 \%$ & 27 & $21.20 \%$ \\
\hline & Normal & 16 & $12.6 \%$ & 11 & $8.7 \%$ & 12 & $9.4 \%$ & 20 & $15.7 \%$ & 59 & $46.40 \%$ \\
\hline & Overweight & 2 & $1.6 \%$ & 5 & $3.9 \%$ & 4 & $3.1 \%$ & 8 & $6.3 \%$ & 19 & $14.90 \%$ \\
\hline & Obese & 4 & $3.1 \%$ & 3 & $2.4 \%$ & 7 & $5.5 \%$ & 8 & $6.3 \%$ & 22 & $17.30 \%$ \\
\hline \multirow{2}{*}{$\begin{array}{l}\text { Neck } \\
\text { girth }\end{array}$} & Normal & 25 & $19.7 \%$ & 21 & $16.5 \%$ & 25 & $19.7 \%$ & 23 & $18.1 \%$ & 94 & $74.00 \%$ \\
\hline & Obese & 2 & $1.6 \%$ & 7 & $5.5 \%$ & 6 & $4.7 \%$ & 18 & $14.2 \%$ & 33 & $15.70 \%$ \\
\hline \multirow[t]{4}{*}{ BP } & Normal & 7 & $5.5 \%$ & 7 & $5.5 \%$ & 4 & $3.1 \%$ & 7 & $5.5 \%$ & 25 & $19.60 \%$ \\
\hline & Pre HTN & 17 & $13.4 \%$ & 14 & $11.0 \%$ & 26 & $20.5 \%$ & 26 & $20.5 \%$ & 83 & $65.40 \%$ \\
\hline & Stage I & 3 & $2.4 \%$ & 7 & $5.5 \%$ & 1 & $0.8 \%$ & 7 & $5.5 \%$ & 18 & $16.50 \%$ \\
\hline & Stage II & 0 & $0.0 \%$ & 0 & $0.0 \%$ & 0 & $0.0 \%$ & 1 & $0.8 \%$ & 1 & $0.80 \%$ \\
\hline \multirow{3}{*}{$\begin{array}{l}\text { Breakfast } \\
\text { eating } \\
\text { habits }\end{array}$} & Daily & 16 & $12.6 \%$ & 13 & $10.2 \%$ & 24 & $18.9 \%$ & 30 & $23.6 \%$ & 83 & $65.30 \%$ \\
\hline & Twice a week & 6 & $4.7 \%$ & 7 & $5.5 \%$ & 3 & $2.4 \%$ & 6 & $4.7 \%$ & 22 & $17.30 \%$ \\
\hline & Thrice a week & 5 & $3.9 \%$ & 8 & $6.3 \%$ & 4 & $3.1 \%$ & 5 & $3.9 \%$ & 22 & $17.20 \%$ \\
\hline
\end{tabular}

On exploratory analysis by Pearson's correlation; substantial inter relationship between studied / modifiable factors was observed there by validating the construct selection. This is presented in Table 2 .

Table 2: Pearson's correlation between modifiable and influencing variables

\begin{tabular}{|c|c|c|c|c|c|c|c|}
\hline $\begin{array}{c}\text { Independent } \\
\text { study variables }\end{array}$ & Gender & Age & BMI & $\begin{array}{c}\text { Systolic } \\
\text { BP }\end{array}$ & Diastolic BP & Neck girth & $\begin{array}{c}\text { Breakfast } \\
\text { frequency }\end{array}$ \\
\hline \multirow{2}{*}{ Gender } & 1 & .060 & .023 & $.207^{*}$ & .125 & $.636^{* *}$ & .064 \\
\cline { 2 - 8 } Age & .060 & 1 & .138 & .055 & .077 & $.194^{*}$ & .472 \\
\cline { 2 - 8 } & .503 & & .121 & .537 & .391 & .029 & .015 \\
\hline \multirow{2}{*}{ BMI } & .023 & .138 & 1 & $.226^{*}$ & $.217^{*}$ & $.387^{* *}$ & -.059 \\
\cline { 2 - 8 } & .797 & .121 & & .011 & .014 & .000 & .510 \\
\hline \multirow{2}{*}{ Systolic BP } & $.207^{*}$ & .055 & $.226^{*}$ & 1 & $.645^{* *}$ & $.192^{*}$ & .012 \\
\cline { 2 - 8 } & .020 & .537 & .011 & & .000 & .030 & .892 \\
\hline \multirow{2}{*}{ Diastolic BP } & .125 & .077 & $.217^{*}$ & $.645^{* *}$ & 1 & .092 & -.005 \\
\cline { 2 - 8 } & .161 & .391 & .014 & .000 & & .304 & .953 \\
\hline Neck girth & $.636^{* *}$ & $.194^{*}$ & $.387^{* *}$ & $.192^{*}$ & .092 & 1 & .030 \\
\hline
\end{tabular}




\begin{tabular}{|l|c|c|c|c|c|c|c|}
\hline & .000 & .029 & .000 & .030 & .304 & & .734 \\
\hline \multirow{2}{*}{$\begin{array}{c}\text { Breakfast } \\
\text { frequency }\end{array}$} & .064 & $-.214^{*}$ & -.059 & .012 & -.005 & .030 & 1 \\
\cline { 2 - 8 } & .472 & .015 & .510 & .892 & .953 & .734 &
\end{tabular}

*correlation is significant at the 0.05 level (2-tailed); ** correlation is significant at the 0.01 level (2-tailed)

Similarly the MCAI demonstrated strong to very strong correlations for its constructs their by lending support for internal validly of the instrument. This is depicted in table number 3.

Table 3: Pearson's correlation between metacognitive awareness inventory, its scales and sub scales

\begin{tabular}{|c|c|c|c|c|c|c|c|c|c|c|c|}
\hline & 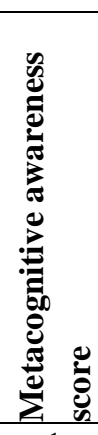 & 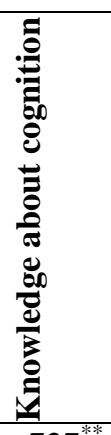 & 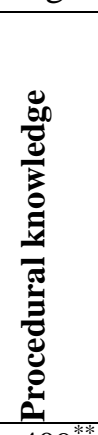 & 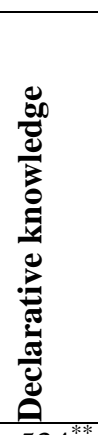 & 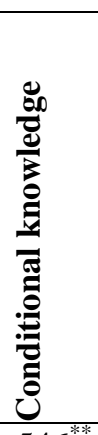 & 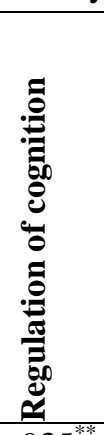 & 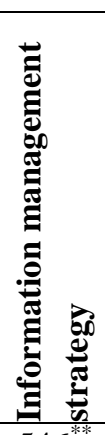 & 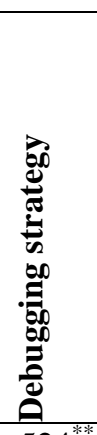 & 兽 & 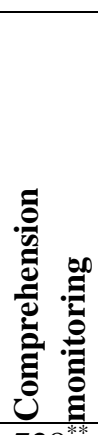 & 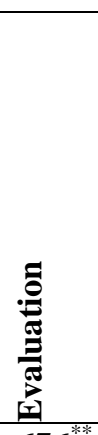 \\
\hline \multirow{2}{*}{$\begin{array}{l}\text { Metacognitive } \\
\text { awareness inventory } \\
\text { score }\end{array}$} & 1 & $.727^{* *}$ & $.409^{* *}$ & $.534^{* *}$ & $.546^{* *}$ & $.935^{* *}$ & $.546^{* *}$ & $.524^{* *}$ & $.705^{* *}$ & $.728^{\frac{6}{* 6}}$ & $.676^{* *}$ \\
\hline & & .000 & .000 & .000 & .000 & .000 & .000 & .000 & .000 & .000 & .000 \\
\hline \multirow{2}{*}{$\begin{array}{l}\text { Knowledge about } \\
\text { cognition }\end{array}$} & $.727^{* *}$ & 1 & $.581^{* *}$ & $.805^{* *}$ & $.628^{* *}$ & $.428^{* *}$ & .165 & $.242^{* *}$ & $.371^{* *}$ & $.385^{* *}$ & $.324^{* *}$ \\
\hline & .000 & & .000 & .000 & .000 & .000 & .063 & .006 & .000 & .000 & .000 \\
\hline \multirow[t]{2}{*}{ Procedural knowledge } & $.409^{* *}$ & $.581^{* *}$ & 1 & $.207^{*}$ & $.197^{*}$ & $.236^{* *}$ & .142 & .056 & .123 & $.253^{* *}$ & $.198^{*}$ \\
\hline & .000 & .000 & & .020 & .026 & .008 & .112 & .529 & .168 & .004 & .026 \\
\hline \multirow{2}{*}{$\begin{array}{l}\text { Declarative } \\
\text { knowledge }\end{array}$} & $.534^{* *}$ & $.805^{* *}$ & $.207^{*}$ & 1 & $.197^{*}$ & $.275^{* *}$ & .082 & $.205^{*}$ & $.212^{*}$ & $.234^{* *}$ & $.254^{* *}$ \\
\hline & .000 & .000 & .020 & & .026 & .002 & .361 & .021 & .017 & .008 & .004 \\
\hline \multirow{2}{*}{$\begin{array}{l}\text { Conditional } \\
\text { knowledge }\end{array}$} & $.546^{* *}$ & $.628^{* *}$ & $.197^{*}$ & $.197^{*}$ & 1 & $.380^{* *}$ & .142 & $.206^{*}$ & $.442^{* *}$ & $.331^{* *}$ & $.206^{*}$ \\
\hline & .000 & .000 & .026 & .026 & & .000 & .110 & .020 & .000 & .000 & .020 \\
\hline \multirow{2}{*}{$\begin{array}{l}\text { Regulation of } \\
\text { cognition }\end{array}$} & $.935^{* *}$ & $.428^{* *}$ & $.236^{* *}$ & $.275^{* *}$ & $.380^{* *}$ & 1 & $.639^{* *}$ & $.562^{* *}$ & $.731^{* *}$ & $.753^{* *}$ & $.717^{* *}$ \\
\hline & .000 & .000 & .008 & .002 & .000 & & .000 & .000 & .000 & .000 & .000 \\
\hline \multirow{2}{*}{$\begin{array}{l}\text { Information } \\
\text { management strategy }\end{array}$} & $.546^{* *}$ & .165 & .142 & .082 & .142 & $.639^{* *}$ & 1 & $.290^{* *}$ & $.312^{* *}$ & $.316^{* *}$ & .173 \\
\hline & .000 & .063 & .112 & .361 & .110 & .000 & & .001 & .000 & .000 & .052 \\
\hline \multirow[t]{2}{*}{ Debugging strategy } & $.524^{* *}$ & $.242^{* *}$ & .056 & $.205^{*}$ & $.206^{*}$ & $.562^{* *}$ & $.290^{* *}$ & 1 & $.334^{* *}$ & $.246^{* *}$ & $.338^{* *}$ \\
\hline & .000 & .006 & .529 & .021 & .020 & .000 & .001 & & .000 & .005 & .000 \\
\hline \multirow[t]{2}{*}{ Planning } & $.705^{* *}$ & $.371^{* *}$ & .123 & $.212^{*}$ & $.442^{* *}$ & $.731^{* * *}$ & $.312^{* *}$ & $.334^{* *}$ & 1 & $.418^{* *}$ & $.399^{* *}$ \\
\hline & .000 & .000 & .168 & .017 & .000 & .000 & .000 & .000 & & .000 & .000 \\
\hline \multirow{2}{*}{$\begin{array}{l}\text { Comprehension } \\
\text { monitoring }\end{array}$} & $.728^{* *}$ & $.385^{* *}$ & $.253^{* *}$ & $.234^{* *}$ & $.331^{* *}$ & $.753^{* * *}$ & $.316^{* *}$ & $.246^{* *}$ & $.418^{* *}$ & 1 & $.517^{* *}$ \\
\hline & .000 & .000 & .004 & .008 & .000 & .000 & .000 & .005 & .000 & & .000 \\
\hline \multirow[t]{2}{*}{ Evaluation } & $.676^{* *}$ & $.324^{* *}$ & $.198^{*}$ & $.254^{* *}$ & $.206^{*}$ & $.717^{* *}$ & .173 & $.338^{* *}$ & $.399^{* *}$ & $.517^{* *}$ & 1 \\
\hline & .000 & .000 & .026 & .004 & .020 & .000 & .052 & .000 & .000 & .000 & \\
\hline
\end{tabular}

*correlation is significant at the 0.05 level (2-tailed); ** correlation is significant at the 0.01 level (2-tailed).

After establishing the validity and reliability ( $\alpha=0.752$, for MCAI and 0.552 for modifiable independent variables) of the tools their inter relationship was studied. On Pearson's correlation scale, an increase in BMI had negative effect on the above all 'metacognition power' ( $\mathrm{r}=-0.191 *)$ along with 'power for regulation of cognition' $\left(\mathrm{r}=-0.197^{*}\right)$, and 'information management strategy' $\left(\mathrm{r}=-0.347^{* *}\right)$. Similar results were observed with respect to systolic blood pressure and 'information managing power' $(\mathrm{r}=-0.244 * *)$. Breakfast skippers also showed 
lower scores in 'knowledge about cognition' $\left(\mathrm{r}=-0.191^{*}\right)$ and 'comprehension monitoring subscales' $\left(\mathrm{r}=-0.180^{*}\right)$ in contrast to regular breakfast eaters. Table number 4 presents the detailed exploratory analysis.

Table 4: Relationship between MCAI scales and exploratory variables

\begin{tabular}{|c|c|c|c|c|c|c|c|}
\hline & Gender & Age & BMI & $\begin{array}{l}\text { Neck } \\
\text { Girth }\end{array}$ & $\begin{array}{l}\text { Systolic } \\
\text { BP }\end{array}$ & $\begin{array}{l}\text { Diastolic } \\
\text { BP }\end{array}$ & $\begin{array}{c}\text { Breakfast } \\
\text { eating Habit }\end{array}$ \\
\hline \multirow{2}{*}{$\begin{array}{l}\text { Metacognitive awareness } \\
\text { inventory score total }\end{array}$} & -.054 & .072 & $-.191^{*}$ & -.102 & -.166 & -.009 & -.165 \\
\hline & .548 & .421 & .032 & .252 & .062 & .916 & .064 \\
\hline \multirow{2}{*}{$\begin{array}{l}\text { Knowledge about } \\
\text { cognition }\end{array}$} & -.114 & .069 & -.071 & -.074 & -.149 & .057 & $-.191^{*}$ \\
\hline & .202 & .443 & .425 & .406 & .096 & .521 & .032 \\
\hline \multirow{2}{*}{ Regulation of cognition } & -.022 & .043 & $-.197^{*}$ & -.085 & -.153 & -.040 & -.101 \\
\hline & .803 & .629 & .027 & .345 & .088 & .658 & .260 \\
\hline \multirow{2}{*}{$\begin{array}{l}\text { Information management } \\
\text { strategies }\end{array}$} & -.005 & .005 & $-.347^{* *}$ & -.158 & $-.244^{* *}$ & -.110 & -.094 \\
\hline & .956 & .958 & .000 & .075 & .006 & .219 & .291 \\
\hline \multirow{2}{*}{ Comprehension } & -.057 & .054 & -.061 & -.077 & -.088 & -.022 & $-.180^{*}$ \\
\hline & .522 & .544 & .495 & .392 & .326 & .810 & .043 \\
\hline
\end{tabular}

*correlation is significant at the 0.05 level (2-tailed); ** correlation is significant at the 0.01 level (2-tailed).

\section{Discussion}

Review of literature exploring the present hypothesis had a low yield. Therefore present discussion has taken into account relevant studies exploring the hypothesized variables employing relating tools like 'PGI memory scale'11, 'P300 evoked potentials', 'the Kaplan-Albert Neuropsychological Test Battery', 'Visual Reproduction Immediate and Delayed Recall tests', and 'Mini-Mental State Examination (MMSE). ${ }^{6}$

Marwa Mohammed Yousif et al in Sudan observed significant relationship between eating behaviour and BMI. ${ }^{13}$ Similar positive association between dietary adherence, BMI and blood pressure in an urban black population in South Africa was also found by other researcher. ${ }^{14}$ It is no secret that obesity is an important correlate of hypertension, ${ }^{15,16}$ and the prevalence of hypertension increases with rising BMI. ${ }^{17,18}$ The correlations among the independent/ exploratory variables in the present study did toe the line established by previous researchers as mentioned above (Table 2).

Awareness of metacognitive knowledge empowers learners by giving them an understanding of how they think. It further helps them to reflect on their strengths and weaknesses as learners and guides them toward remedial measures. Schraw and Dennison (1994) developed the Metacognitive Awareness Inventory (MAI) to assess metacognitive knowledge and metacognitive regulation which they referred to as the knowledge of cognition factor and the regulation of cognition factor. The MAI consists of 52 questions tapping into these two components of metacognition. They found that there was strong support for the knowledge of cognition and regulation of cognition components and that these two components were related. ${ }^{19}$ The present study also demonstrated strong to very strong co relationship among the different constructs of the adopted MCAI toll (Table 3).

Having established the fact that the MCAI and its sub sections, and the independent variables demonstrated intra group correlation; an attempt was made to find any correlations between the dependant and independent variables. It was found that participants with higher BMI scored poorly in metacognitive awareness inventory score $(\mathrm{r}=-0.191 *)$, regulation of cognition $\left(\mathrm{r}=-0.197^{*}\right)$, and information management strategy $(\mathrm{r}=-0.347 * *)$ that may implicate obese participants might be poor learners, and less equipped in handling day to day situation. Framingham Heart Study had shown that obesity is associated with accelerated cognitive decline in aging men. ${ }^{14}$ A study conducted in southern Ethiopia had 
demonstrated similar observations where adolescents with normal BMI had good learning potential. ${ }^{3}$

Participants who had high systolic blood pressure had relatively less skills in processing information strategies $\left(\mathrm{r}=-0.244^{* *}\right)$ as compared to those with normal systolic blood pressure. Study on relationship between blood pressure and cognitive function showed that both hypertension and hypotension affect brain perfusion and worsen cognitive outcome. ${ }^{9}$

Breakfast eating frequency showed negative correlation with knowledge about cognition and comprehension $(r=-0.191 *,-0.180 *$ respectively) i.e. less frequent eaters had poor cognitive ability. A study conducted on perceptual development of adolescents in relation to nutritional status with the help of picture ambiguity test (PAT) reported that there was a significant difference in the performance of wellnourished and undernourished adolescents during this test (PAT). ${ }^{13}$ Another study, conducted on school children reported that skipping breakfast can have adverse effects on cognitive performance. ${ }^{14}$ Alternatively, breakfast skippers run the risk of becoming malnourished which had been linked to delayed cognitive development. ${ }^{3}$ All these observations lend support to our hypothesis.

\section{Conclusion}

Metacognitive awareness inventory is a welldocumented and scientifically proven comprehensive tool to assess the intellectual ability of a person. This Study was a first timer where MCAI was explored in terms of common modifiable factors in day today life of medical students. Inculcation of healthy life style can be a profound booster to learning abilities. Healthy eating, maintain normal BMI and blood pressure can put a professional student on an advantageous platform.

\section{Strength and weakness}

MCAI was found to have high construct validity and internal consistency in the present context. Conduction of study in a systematic and phased manner with effective time capping was able to minimize respondent / information bias. A follow up study over subsequent years and association with their academic performance can further add on to the present evidence.

\section{Acknowledgement}

Authors are grateful to the students for their whole hearted and enthusiastic support during the study period. We are also thankful to our departmental staffs for their cooperation.

\section{Ethics clearance}

The study received IEC clearance via, IEC approval letter No. 69/2019.

\section{Conflict of Interest}

The authors declare no conflicts of interest.

\section{Financial Support}

Nil. The study was self financed.

\section{References}

1. Hong WH, Vadivelu J, Daniel ES, Sim JH. Thinking about thinking: changes in first-year medical. Med Education Online 2015;79(1):1-8.

2. Spence C. Breakfast: The most important meal of the day? Int J Gastronomy Food Sci 2017;8(1):1-6.

3. Adole AA, Singh P, Bosha T, Desalegn BB. Effect of Breakfast Eating Patterns and Anthropometric Measurements on Cognitive Function of Early Adolescents in Rural Area of Sidama Zone, Southern Ethiopia. Journal of Food and Nutrition Sciences. 2015;3(6):251-258.

4. Wang C, Chan JS, Ren L, Yan JH. Obesity reduces cognitive and motor functions across the lifespan. Neural plasticity. 2016;http://dx.doi.org/10.1155/2016/2473081 accessed on 20-11-2019:1-13 .

5. Elias MF, Elias PK, Sullivan LM, Wolf PA, D'agostino RB. Lower cognitive function in the presence of obesity and hypertension: the Framingham heart study. Int J Obes 2003;27(2):260-8.

6. Sabia S, Kivimaki M, Shipley MJ, Marmot MG, SinghManoux A. Body mass index over the adult life course and cognition in late midlife: the Whitehall II Cohort Study. Am J Clin Nutr 2008;89(2):601-7.

7. Gąsecki D, Kwarciany M, Nyka W, Narkiewicz K. Hypertension, brain damage and cognitive decline. Curr Hypertens Rep 2013;15(6):547-58.

8. Elias MF, Goodell AL, Dore GA. Hypertension and cognitive functioning: a perspective in historical context. Hypertens 2012;60(2):260-8.

9. Pachucki MA. Food pattern analysis over time: unhealthful eating trajectories predict obesity. Int J Obes 2012;36(5):686-94. 
10. Iadecola C, Yaffe K, Biller J, Bratzke LC, Faraci FM, Gorelick PB et al, Impact of hypertension on cognitive function: a scientific statement from the American Heart Association. Hypertens 2016;68(6):67-94.

11. Gajre NS, Fernandez S, Balakrishna N, Vazir S. Breakfast eating habit and its influence on attention-concentration, immediate memory and school achievement. Indian Pediatr 2008;45(10):824-28.

12. Agarwal S, Bhalla P, Kaur S, Babbar R. Effect of body mass index on physical self-concept, cognition \& academic performance of first year medical students. Indian J Med Res 2013;138(4):515-22.

13. Yousif MM, Kaddam LA. \& Humeda HS. Correlation between physical activity, eating behavior and obesity among Sudanese medical students Sudan. BMC Nutr 2019;5(6). doi:10.1186/s40795-019-0271-1.

14. Solomons N, Kruger HS, Puoane T. Association between dietary adherence, anthropometric measurements and blood pressure in an urban black population, South Africa. South Afr J Clin Nutr 2018:1-9.

15. Kuwabara M, Kuwabara R, Niwa K, Hisatome I, Smits G, Roncal-Jimenez $\mathrm{C}$ et al, Different risk for hypertension, diabetes, dyslipidemia, and hyperuricemia according to level of body mass index in Japanese and American subjects. Nutr 2018;10(8):1-11.

16. Kapetanakis VV, Rudnicka AR, Wathern AK, Lennon L, Papacosta O, Cook DG et al, Adiposity in early, middle and later adult life and cardiometabolic risk markers in later life; findings from the British regional heart study. PLoS One 2014;9(12):1-17.

17. Lee CY, Lin WT, Tsai S, Hung YC, Wu PW, Yang YC et al, Association of parental overweight and cardiometabolic diseases and pediatric adiposity and lifestyle factors with cardiovascular risk factor clustering in adolescents. Nutr 2016;8(9):567:1-14.

18. Crawford AG, Cote C, Couto J, Daskiran M, Gunnarsson C, Haas K et al, Prevalence of obesity, type II diabetes mellitus, hyperlipidemia, and hypertension in the United States: findings from the GE Centricity Electronic Medical Record database. Popul Health Manag 2010;13(3):151-61.

19. Schraw G, Dennison RS. Assessing metacognitive awareness. Contemp Educ Psychol 1994;19(4):460-75.

20. Mahmoud MH, Taha AS. The association between eating habits and body mass index among nursing students. IOSR J Nurs Health Sci (IOSR-JNHS). 2017;6(3):14-26.

21. MacMahon S, Peto R, Collins R, Godwin J, Cutler J, Sorlie $\mathrm{P}$ et al, Blood pressure, stroke, and coronary heart disease: part 1, prolonged differences in blood pressure: prospective observational studies corrected for the regression dilution bias. Lancet 1990;335(8692):765-74.

22. Jellinger KA, Attems J. Prevalence of dementia disorders in the oldest-old: an autopsy study. Acta Neuro Pathologica 2010;119(4):421-33

23. Nelson PT, Head E, Schmitt FA, Davis PR, Neltner JH, Jicha GA et al, Alzheimer's disease is not "brain aging": neuropathological, genetic, and epidemiological human studies. Acta Neuropathologica 2011;121(5):571-87.

24. Barodka VM, Joshi BL, Berkowitz DE, Hogue Jr CW, Nyhan D. Implications of vascular aging. Anesth Analgesia 2011;112(5):1048-68.

25. Chhabra P, Grover VL, Aggarwal K, Kanan AT. Nutritional status and blood pressure of medical students in Delhi. Indian J Community Med 2006;31(4):248-51.

26. Bellisle F. Effects of diet on behaviour and cognition in children. Br J Nutr 2004;92(S2):227-32.

27. Upadhyay SK, Singh TB, Srivastava A, Bhatia BD. Perceptual development in relation to nutritional status. Indian J Paediatr 2001;68(4):327-32.

How to cite this article: Mishra BN, Barjatya $\mathrm{P}$, Panwar NKS, Chouhan DS, Mohapatra SC. Study of modifiable risk factors associated with learning abilities in MBBS students. J Community Health Manag 2019;6(4):98-104. 